\title{
Pro-con debate: Inhaled corticosteroids should not be prescribed in primary care to children under two years of age - the case against
}

\author{
*Warren Lenney \\ a Professor of Respiratory Child Health, Academic Department of Child Health, UHNS and Keele University, Stoke-on-Trent, UK
}

Received 29th April 2008; revised version received 2nd July 2008; accepted 6th July 2008; online 5th September 2008

\begin{abstract}
Asthma is difficult to diagnose in children under 2 years of age and there is a dearth of clinical studies using inhaled corticosteroids in this age group. Guidelines advise caution in both diagnosis and treatment but do recommend a trial of inhaled corticosteroids if respiratory symptoms are severe. Clinical studies have been published showing symptoms can be improved with inhaled corticosteroid usage. If their dosages are kept well within the licensed range the risks of adverse events and clinically relevant side effects are small. To deny very young children the opportunity of clinical benefit from the use of inhaled corticosteroids in this age group is not acceptable. Processes need to be in place to ensure inhaler technique is adequate and assessmentof clinical outcomes is robust.
\end{abstract}

(c) 2008 General Practice Airways Group. All rights reserved.

W Lenney. Prim Care Resp J 2008; 17(3): 181-184.

doi:10.3132/pcrj.2008.00054

Keyw ords paediatrics, asthma, chronic, management, primary care, guideline, inhaled corticosteroids

\section{Introduction}

It is always dangerous in medical debate to state categorically "thou shalt not", whatever the subject of the debate. The issue is compounded when discussing management in children due to the lack of evidence-based information - and if extrapolating to children under two years of age the evidence is almost non-existent. Therefore, in terms of the question for debate here; firstly, one should tread with caution, since dogmatic views are rarely the ones to follow. Secondly, clinicians are trained to understand both health and disease, and are in an excellent position to decide options on the grounds of clinical probability - for example, whether or not it is worth trying one particular medication in a very young child. Over the past 15 years we have seen three UK national asthma guidelines developed relating to the management of asthma in both children and adults. ${ }^{1 \cdot 3}$ Similar guidelines have been developed by the Global Initiative on Asthma (GINA) as well as others from many countries of the world including the USA and Australia. I certainly don't recall any of these prestigious documents saying "do not prescribe inhaled corticosteroids (ICS) in the community in the first two years of life". I accept that there is concern about excessive use of ICS and increasing use of ICS in high dosages. I maintain, however, that these are different issues and not applicable to this debate.

\section{Cellular inflammation in the airways}

Inhaled corticosteroids are the cornerstone of asthma management in all other age groups. Is there really any evidence to say they do not work in the first two years of life, assuming that we make an appropriate diagnosis of childhood asthma? I think not. Any argument based on the type of cellular inflammation seen in the airways is extremely tenuous because information in the very young child is minimal, and studies are limited to one or two tertiary centres whose clientele are hardly the same as those attending an average general practice surgery. Even in adults, it is well recognised that neutrophils, eosinophils, lymphocytes and

\footnotetext{
* Corresponding author: Professor Warren Lenney, Child Health, UHNS, Newcastle Road, Stoke-on-Trent, Stoke, ST4 6QG, UK. Email: Warren.Lenney@uhns.nhs.uk
} 
macrophages all play a role, and the presence or absence of one or all of these cells within the airways does not influence prescribing in primary care..$^{4-6}$

\section{The importance of considering differential diagnoses}

I suspect the opposing view to mine will state that clinicians prescribe ICS for a very large percentage of extremely young children with repeated respiratory symptoms, inflicting on them the possibility of severe side effects such as growth retardation and hypoglycaemic coma caused by suppression of the pituitary-adrenal axis.7.8 I cannot condone such practices, but I can condone - and do recommend - a trial of low dose ICS in carefully selected young children. I had hoped that the days of the primary or secondary care clinician sitting in the surgery or clinic, pen in hand, ready to write a prescription without carefully considering the differential diagnosis had long since passed...

The first clinical decision is to consider the differential diagnosis and to try and rule out other possible causes of chronic respiratory symptoms such as gastro-oesophageal reflux or problems related entirely to the nasal passages and the pharyngeal region. The second clinical decision is to assess the severity of the symptoms and decide whether reassurance can be given to the family without the need to offer specific treatment. The upper airways are very narrow and small in the first few years of life; secretions can partially block and obstruct the child's breathing, resulting in rattles and noisy breathing. Viral respiratory pathogens such as rhinovirus are common and occur a number of times per year over the winter months in the first and second years of life. Simple discussion with the parents may be all that is required to deal with minor problems. However, when recurrent respiratory symptoms affect the child's feeding and/or sleeping, and it appears that the problem arises from below the inlet of the thorax, specific therapy should be considered.

\section{Early risk factors for developing asthma}

Most children who develop chronic asthma in later childhood will have their early symptoms within the first three years of life. ${ }^{9}$ Clinically, these children are extremely difficult to differentiate from those who have recurrent symptoms but who become asymptomatic by the age of six..$^{10}$ There are, however, risk factors which have been identified and which make the continuation of symptoms more likely. These are: a previous history in the child's first year of life of allergy to milk, eggs or other foods; a history of eczema as a baby; or a family history of asthma or atopy.

\section{Studies on ICS use in very young children} The first study specifically to report the benefits of ICS in very young children was published in 1990. ${ }^{11}$ The age range of the children in this study was 1-4 years, and at the time most clinicians agreed that it confirmed their clinical views about the use and benefit of ICS in very young children. Contrast this study with one undertaken using cromoglycate in the same age group where no treatment benefit was seen. ${ }^{12}$ It is interesting that, ten years on, cromoglycate is no longer used in this young age group or, indeed, in older children with a diagnosis of asthma. Doctors aim to be responsible prescribers, and I really believe that if ICS did not work in specific age groups they would not continue to prescribe them.

In the 1990's, other studies in very young children with severe asthma showed that budesonide - via a metered-dose inhaler plus spacer and face mask or via nebuliser - was effective. ${ }^{13,14}$ The results in children with viral-induced wheeze were less good, but the results showed that there was some response compared with placebo, even though it was less than in children with true ato pic asthma. ${ }^{15,16} \mathrm{~A}$ comprehensive study was published in the American Journal of Respiratory and Critical Care Medicine in 1999;17 237 children, aged 12-47 months, were recruited into this multi-centred, randomised, double blind, parallel group, placebo-controlled study. Following a four-week run-in period the children entered a 12-week treatment course receiving either placebo, fluticasone propionate (FP) $50 \mathrm{mcg}$ twice-daily (FP100) or fluticasone propionate $100 \mathrm{mcg}$ twice-daily (FP200). Treatment was given through a metered-dose inhaler and a specially-designed spacing device for very young children, including a face mask (Babyhaler ${ }^{T M}$ ). With FP200 there was a statistically significant improvement from baseline compared with the placebo group in eight of 10 diary card parameters, including the symptom domains of wheeze, cough, breathlessness, and reduced use of rescue medication. FP100 produced a significant reduction in five of the 10 parameters, compared with placebo. The percentage of patients with at least one exacerbation during the treatment period was $37 \%$ with placebo, $26 \%$ with FP100 and $20 \%$ with FP200. The difference between placebo and FP200 was statistically significant. The conclusions from this study were that asthmatic symptoms in children aged one to four years old respond in a significant and dose-related manner to treatment with $\mathrm{FP}$ within a licensed paediatric dose range.

A more recent study was undertaken in the USA assessing the benefit of ICS in preschool children. This study, known as the PEAK Study (the Prevention of Early Asthma in Kids), was set up to answer whether ICS can modify the subsequent development of asthma in preschool children with a high risk of developing asthma. ${ }^{18}$ Two hundred and eighty-five children, with a median age of 3 years, took part. The age of onset of the asthma symptoms was $<1$ year of age. The study 
continued for a three-year period. In the first two years treatment was given using FP $100 \mathrm{mcg}$ twice daily or placebo. The third year was an open observational period without any study medication, the primary outcome being the proportion of episode-free days during the observation year. Although by the end of the third observational year there was no difference in the proportion of episode-free days, during the two-year treatment period the proportion of symptom-free days in those children receiving ICS was $94.9 \%$ compared to $88.4 \%$ in the placebo group. Therefore, although ICS did not modify symptoms after the two-year period, there was clear evidence that the episodes of wheeze were less during the two-year active treatment period with ICS when compared with children treated with placebo. There has never been any study undertaken which has shown that any medication, either in childhood, in adolescence or in adult life has any effect on the natural history of the progression of asthma. Therefore, like all the other studies attempting to answer such a question, this study failed to affect long-term outcome but as with the previous studies I have discussed, there was a positive benefit in terms of reduced symptomatology whilst the children were taking ICS therapy.

\section{Lung function studies in very young children}

Lung function studies are very difficult to undertake in very young children. However, Devulapalli and coHeagues measured tidal flow-volume curves in infants receiving ICS and showed a beneficial effect of ICS treatment. Another study by Moeller et al showed that inhaled FP decreased the levels of nitric oxide in recurrently wheezy infants. ${ }^{20}$ Teper et al treated children with ICS or placebo for a six-month period. All the children were under two years of age. There was a statistically significant benefit for ICS in terms of lung function, the need for rescue medication, and the percentage of symptom-free days. ${ }^{21}$

Although not all studies in very young children have shown ICS to be clinically and significantly beneficial, the UK study by Chavasse and colleagues, published in 2001, showed that persistent wheezing in infants with an atopic tendency responded to inhaled FP. ${ }^{22}$

\section{Low rates of ICS side effects in young children}

There is the possibility of side effects from ICS therapy in the very young age group. However, despite many studies having been undertaken, when ICS have been used at licensed dosages side effects have been uncommon. For instance, in the Bisgaard study over a 3-month period, ${ }^{17}$ the adverse event profile differed little among the three treatment groups of placebo, FP 100, and FP $200 \mathrm{mcg}$ daily. Asthma was the most commonly reported adverse event, and fever and upper respiratory tract infections were also common. Skin rashes and throat irritation were similar in all three groups, and evidence of oral Candida was seen in $6 \%$ on placebo, $10 \%$ on FP 100 and $4 \%$ on FP 200 . Serious adverse events were very rare and were not related to the treatment itself.

Teper et $\mathrm{al}^{21}$ measured growth velocity over a 6-month period in children receiving FP 125 or placebo; there was no statistically significant difference between the groups at the end of the study period. Bisgaard et al ${ }^{23}$ compared intermittent use of budesonide $400 \mathrm{mcg}$ or placebo in the first three years of life, and there was no difference between the two groups in growth measured by stadiometry or in bone mineral density measurements. In a 3-month study comparing efficacy of FP 200 versus placebo on lung function and symptoms in 65 wheezy infants, no differences were seen in height increase and no child developed oral candidiasis; three serious adverse events were all considered unrelated to wheezing or the treatment used. ${ }^{24}$ Finally, in the PEAK study, growth velocity was lower in the FP group than in the placebo group after 10 months but both groups had the same growth velocity at 24 months and in the open study over the following 12 months the growth velocity was higher in those chitdren who had initially been given $\mathrm{FP}^{18}$

\section{Use of ICS as a trial of treatment in primary care}

National guidelines make appropriate reference to the difficulty of diagnosis in relation to recurrent respiratory symptoms in very young children. The evidence I have presented is, I believe, sufficient to warrant a trial of ICS in very young children with persistent wheezing in the same manner as that in older children. Although there is evidence that improvements in symptoms and lung function can take place many months after commencing ICS, it is highly likely that clinical improvement, if it is to take place, will occur within six weeks of starting ICS treatment. The long-term use of diary cards is not helpful but it can aid the practitioner in determining reduction in symptoms and use of relief treatment in this young age group - as is commonly practised in older children. Simple questioning of parents/carers as to whether they feel the child is better may alone be sufficient to establish, or refute, the benefit. Failure to respond to a trial of ICS within six weeks should certainly prompt re-evaluation rather than an immediate increase in treatment. If ICS are commenced and there is no beneficial effect, clinical guidelines would recommend they be discontinued.

An important cause of treatment failure in this age group is inadequate drug delivery. Mask and spacer devices are not easy to use and there is a misconception that if the child is crying this will increase drug delivery whereas the reverse is 
true. The help of a skilled and fully-trained respiratory nurse is essential in helping to manage very young children with respiratory problems and should be an important part of the primary care armamentarium.

\section{Conclusion}

The evidence for the use of ICS in the first two years of life is probably as strong as it is for any other form of respiratory therapy in this young age group. In primary care, to deny such children the opportunity of response to treatment with ICS is as irresponsible as treating all patients with ICS who have mild recurrent respiratory symptoms.

\section{Conflict of interest declaration}

The author is a member of the Paediatric Clinical Advisory Boards of GSK, MSD and Novartis and holds an educational grant from GSK to study parental understanding of asthma control.

\section{References}

1. Guidelines on the Management of Asthma. Thorax 1993;48(Suppl 2):S1-24.

2. The British Guidelines on Asthma Management: 1995 Review and position statement. Thorax 1997;52(Suppl 1):S1-21.

3. British Guideline on the Management of Asthma. Thorax 2003;58(Suppl 1):I 194.

4. Bentley AM, Maestrelli P, Saetta M, et al. Activated T-lymphocytes and eosinophils in the bronchial mucosa in isocyanate-induced asthma. J Allergy Clin Immunol 1992;89:821-9.

5. Azzawi M, Bradley B, Jeffery PK, et al. Identification of activated T-lymphocytes and eosinophils in bronchial biopsies in stable atopic asthma. Am Rev Respir Dis 1990; 142:1407-13.

6. Payne DNR, Adcock IM, Wilson NM, et al. Relationship between exbaled nitric oxide and mucosal eosinophilic inflammation in children with difficult asthma, after treatment with oral prednisolone. Am J Respir Crit Care M ed 2001;164: 1376-81.

7. Todd GR, Acerini $C L$, Ross-Russell $R$, et al. Survey of adrenal crisis associated with inhaled corticosteroids in the United Kingdom. Arch Dis Child 2002;87: 457-61.

8. Drake AJ, Howells RJ, Shield JP, et al. Symptomatic adrenal insufficiency presenting with hypoglycaemia in children with asthma receiving high dose inhaled fluticasone proprionate. BMJ 2002;324:1081-2.

9. Gerritsen J, Koeter GH, Postma DS, et al. Prognosis of asthma from childhood to adulthood. Am Rev Respir Dis 1989;140:1325-30.

10. Martinez FD, Wright AL, Taussig LM, et al. 1995. Asthma and wheezing in the first six years of life. N Engl J Med 1995;332:133-8.

11. Bisgaard H, Munck SL, Nielsen JP, et al. Inhaled budesonide for treatment of recurrent wheezing in early childhood. Lancet 1990;336:649-51.

12. Tasche MJA, van der Wouden JC, Uijen JHJM, et al. Randomised placebocontrolled trial of inhaled sodium cromoglycate in 1-4 year old children with moderate asthma. Lancet 1997;350:1060-4.

13. Connett, GJ, Warde C, Wooler E, W Lenney. Use of budesonide in severe asthmatics aged 1-3 years. Arch Dis Child 1993;69:351-5.

14. De Blic J, Delacourt C, Le Beourgeois M, et al. Efficacy of nebulised budesonide in treatment of severe infantile asthma: a double-blind study. J Allergy Clin Immunol 1996;98:14-20.

15. Connett $\mathrm{G}$, Lenney W. Prevention of viral induced asthma attacks using inhaled budesonide. Arch Dis Child 1993;68:85-8.

16. Wilson NM, Silverman M. Treatment of acute, episodic asthma in pre-school children using intermittent high dose inhaled steroids at home. Arch Dis Child 1990;65:407-10.

17. Bisgaard H, Gillies J, Groenewald M, M aden C. The effect of inhaled fluticasone propionate in the treatment of young asthmatic children. Am J Respir Crit Care Med 1999;160:126-31

18. Guilbert TW, M organ WJ, Zeiger RS, et al. Long term inhaled corticosteroids in preschool children at high risk of asthma. NEJM 2006;354:1985-97.

19. Devulapallic $\mathrm{C}$, Haaland $G$, Pettersen $M$, et al. Effect of inhaled steroids on lung function in young children: a cohort study. Eur Respir J 2004;23:869-75.

20. Moeller A, Eranklin P, Hall GL, et al. Inhaled fluticasone dipropionate decreases levels of hitric oxide in recurrently wheezy infants. Pediatr Pulmonol 2004; 38:250-5.

21. Teper AM, Kofman CD, Szulman GA, et al. Fluticasone improves pulmonary function in children under 2 years old with risk factors for asthma. Am J Respir Crit Care Med 2005;171:587-90.

22. Chavasse RJ, Bastian-Lee $\mathrm{Y}$, Richter $\mathrm{H}$, et al. Persistent wheezing in infants with an atopic tendency responds to inhaled fluticasone. Arch Dis Child 2001;85: 143-8.

23. Bisgaard $\mathrm{H}$, Hermansen $\mathrm{MN}$, Loland L, et al. Intermittent inhaled corticosteroids in infants with episodic wheezing. NEJM 2006;354:1998-2005.

24. Hofhuis W, van der Wiel EC, Nieuwhof EM, et al. Efficacy of fluticasone propionate on lung function and symptoms in wheezy infants. Am J Respir Crit Care Med 2005;171:328-33.

\section{Available online at http://w w w.thepcrj.org}

